\title{
Reliability Dynamic Analysis by Fault Trees and Binary Decision Diagrams
}

\author{
Fausto Pedro García Márquez ${ }^{1, *}$, Isaac Segovia Ramírez ${ }^{1}$, Behnam Mohammadi-Ivatloo ${ }^{2, *}$ (C) \\ and Alberto Pliego Marugán ${ }^{3}$ \\ 1 Ingenium Research Group, University of Castilla-La Mancha, 13071 Ciudad Real, Spain; \\ isaac.segovia@uclm.es \\ 2 Faculty of Electrical and Computer Engineering, University of Tabriz, Tabriz 5166616471, Iran \\ 3 Business \& Marketing School, ESIC, 28043 Madrid, Spain; alberto.pliego@esic.edu \\ * Correspondence: faustopedro.garcia@uclm.es (F.P.G.M.); bmohammadi@tabrizu.ac.ir (B.M.-I.); \\ Tel.: +34-(926)-6295300 (ext. 6230) (F.P.G.M.); +98-41-3334-0081 (B.M.-I.)
}

Received: 29 April 2020; Accepted: 11 June 2020; Published: 15 June 2020

\begin{abstract}
New wind turbines are becoming more complex and reliability analysis of them rising in complexity. The systems are composed of many components. Fault tree is used as an useful tool to analyze these interrelations and provide a scheme of the wind turbine, to get a quick overview of the behavior of the system under certain conditions of the components. However, it is complicated and in some cases not possible, to identify the conditions that would generate a wind turbine failure. A quantitative and qualitative reliability analysis of the wind turbine is proposed in this study. Binary decision diagrams are employed as a suitable and operational method to facilitate this analysis and to get an analytical expression by the Boolean functions. The size of the binary decision diagram, i.e., the computational cost for solving the problem, has an important dependence on the order of the components or events considered. Different heuristic ranking methods are used to find an optimal order or one closed, and to validate the results: AND, level, top-down-left-right, deep-first search and breadth-first-search. Birnbaum and criticality importance measures are proposed to evaluate the relevance of each component. This analysis leads to classify the events according to their importance with respect to the probability of the top event. This analysis provides the basis for making medium and long-term maintenance strategies.
\end{abstract}

Keywords: fault tree; binary decision diagrams; wind turbines; maintenance management; wind energy; dynamic analysis

\section{Introduction}

Wind energy is one of the fasting-growing renewable energies because of the new wind turbines (WT), becoming higher and more complex, i.e., with more power electric generation [1]. It is expected that new installations will increase more than 55 GW every year until 2023 [2], see Figure 1.

A WT is composed of static parts, e.g., tower or support, blades and nacelle and rotative or mechanical components, e.g., hubs, gearbox or generator. These components are exposed to physical efforts, e.g., stress or compression and chemical or environmental conditions such as erosion or surface degeneration [3]. During the operation of the installations, mechanical or electrical failures appear due to the working conditions $[4,5]$. 


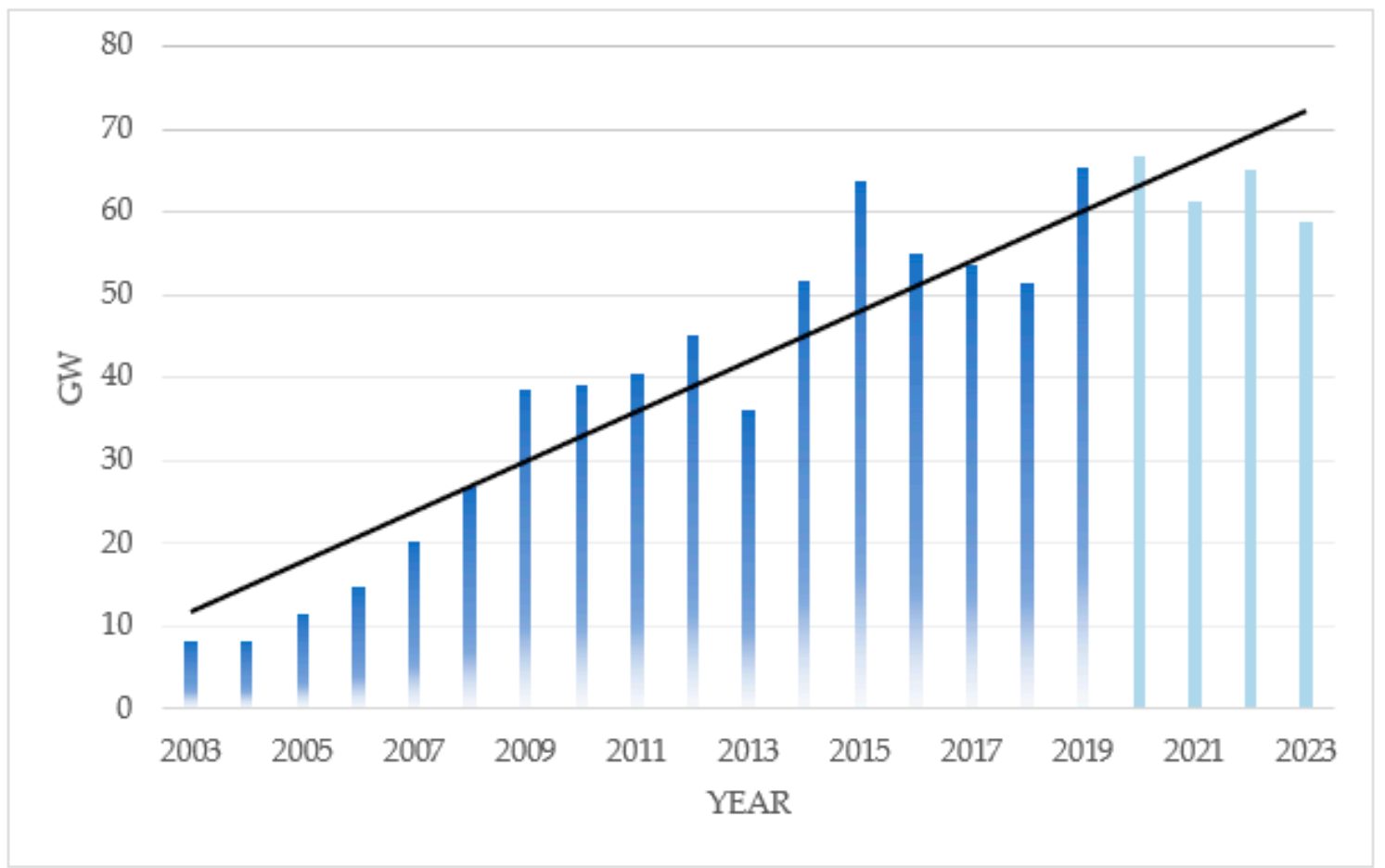

Figure 1. Wind energy capacity and forecast [2].

Njiri and Soeffker [6] showed that WTs are employing new designs, electronic, materials, electrical, mechanical and control systems. This is leading to increased production capacity and improved competitiveness [1,7]. These new strategies-together with the data available and the advanced analytics-are favoring system efficiency and cost-reduction [8,9]. Good maintenance policies have been demonstrated to be a key factor in this efficiency and cost-reduction $[10,11]$. The reliability of WTs depends on correct maintenance management $[12,13]$. The localization and the environment conditions-together with the complexity of the WTs-drives maintenance operations to become complicated [14]. The main maintenance tasks, preventive and corrective, required to be done over the time [15] are expensive and generate risks. The maintenance costs are between $12 \%$ and $23 \%$ of the total costs $[16,17]$.

WTs are monitored to improve the efficiency of maintenance management by supervisory control and data acquisition (SCADA) systems [18]. SCADA integrates all measurements by sensors and measurement systems. SCADA monitors signals and alarms with a range acquisition period per minute or per ten minutes. Alarm activations display anomalies or failures detected by the sensors, though they may induce false alarms due to incorrect analysis or non-defined failures [19]. Since these failures reduce system accuracy, novel algorithms for false alarm detection and identification are needed [11]. The generation of false alarms by a SCADA system is a fundamental issue due to unnecessary stops, false interventions by the maintenance team and loss of productivity [20,21]. Several researches are based on the detection and reduction of WTs false alarms by different advanced analytics [22,23]. Condition monitoring system (CMS) is used to reduce the false alarms rates. CMS leads to apply predictive maintenance policies [24].

A maintenance strategy more employed is the so-called condition-based maintenance (CBM), i.e., maintenance based on the diagnosis of a WT to intervene only if the equipment requires it [4]. This optimizes the time employed on maintenance, additional costs to maintenance and equipment reliability [25-27]. Many of these tasks involve the replacement of certain components due to the exhaustion of their estimated useful life [28-30]. The strategy based on the prior analysis of the equipment condition before deciding which interventions to carry out is a successful and optimal strategy for equipment related to electricity generation [31,32]. There are different techniques to 
monitoring the WT performance, such as ultrasound, thermography, radiography, acoustics emissions, etc. [33,34].

The methodologies for fault detection and diagnosis in WTs are classified into model or data type $[5,35,36]$. The method analysis uses mathematical models developed with the comprehension of the physical behavior of the WT [37]. The volume and number of variables provided by the CMS involve different types of analysis for extracting the real condition of the WT [15]. Fault tree analysis (FTA) is a qualitative analysis for representing graphically the connections between the conditions and effects of the component faults [38]. Binary decision diagrams (BDD) on fault tree (FT) allow the quantitative analysis and the identification of the critical components of each WT, identifying the critical risks $[39,40]$. BDD is data structure employed to show a Boolean function, which facilitates scalable constructions of Boolean functions using reversible logic gates [41].

Quantitative techniques are obtained by mathematical models from the probabilities of the events $[42,43]$. The analysis purposed in this study estimates the probability of the top event taking into consideration the conditions of the main components. A quantitative analysis is done employing the BDD analyzing the Boolean function. The computational cost is reduced employing the event ranking methods: top-down-left-right, level, AND, breadth-first-search and depth-first-search. The importance measures (IM) are obtained by the Birnbaum and criticality methods, i.e., the results are validated by both methods. The reliability analysis aims to achieve an efficient maintenance strategy to keep the unreliability of the system below of a desired threshold. To achieve this aim, it is essential to define two factors: when the repairs should be made and the components that should be repaired. The first one is determined by the intersection between the unreliability of the system and the threshold. The second one is obtained by IMs (IMs): Birnbaum or criticality. An iterative process is suggested to define a strategy able to ensure a correct reliability for a certain period of time.

The main novelties presented in this study are:

- An optimization of the maintenance management is employed based on IMs;

- An iterative process is suggested to define a strategy to ensure a correct reliability for a certain period of time.

Section 2 introduces the FTs and BDDs. A novel dynamic analysis is proposed in Section 3. The IMs are shown and discussed in Section 4 . The new procedure for maintenance is described in Section 5. Finally, Section 6 presents the main conclusions.

\section{FTs and BDD for Reliability Analysis}

\subsection{Background}

FTs are a common approach for analyzing a whole system by considering all the main components that compound the system. The components, also known as elements, are related by the logical gates or logical operators "AND" and "OR". It can be also included other logical operators, but only these ones will be used in this study. The components together with the logical operators will compound the FTs [44].

The top event analysis is done by quantitative evaluation, where the main methods can be classified as direct evaluation methods and methods based on the use of prime implicant (PI) sets. The conventional methods show some drawbacks, for example, the FT size and the complexity of the FT. It leads to high computational costs and some methods cannot be applied due to the complexity of the problem.

Li et al. [45] showed that there are similar approaches to FTA, such as reliability block diagrams (RBD) and Bayesian networks [46]. They suggest automatic transformation methods for converting the function principle graphs, e.g., Markov models [47], to FTs [48,49] or RBDs [50]. The dynamic FT (DFT) or dynamic RBD can be transformed into a dynamic Bayesian network to estimate the reliability [51-53]. 
Large combinations of AND/OR gates make calculations difficult and increase the computational cost. Rauzy employed methods based on BDDs to obtain the IMs with exact results $[54,55]$. BDDs present the following advantages [56]:

- The computational cost is independent of the number of PIs and the way in which the FT is built;

- All the PIs are taken into account; they provide exact qualitative and quantitative information;

- The computational speed is between 100-1000 times higher than using classic methods;

- Typical operators of Boolean algebra can be evaluated with quadratic complexity;

- The cost of the analysis using BDD depends on the FT size;

- Large Boolean functions can be represented with relatively small diagrams;

- Operations with "products" over the time are linear with respect to the BDD size;

- Great efficiency in the treatment of non-coherent FTs.

\subsection{Case Study}

The approach was employed to analyze the generator, electrical and electronic components that are installed inside the nacelle. Faults in generators can be the result of electrical or mechanical causes [57]. The main electrical faults are due to open-circuits or short-circuits in the rotor or stator [58] that could cause overheating [37]. Previous research works have demonstrated that bearings involve a high failure rate in WTs [59]. The bearings failures of the generator are usually caused by cracks, asymmetry and imbalance [60]. Short-circuit, open-circuit and gate-drive circuit faults are the three major electrical faults of the power electronics and electric controls in WTs [39]. Table 1 shows the main elements and failures in the generator, electrical and electronic components.

Figure 2 shows the FT from Table 1 for a WT. It has twelve basic components and ten non-basic components. Basic components are not possible to be broken down into simpler causes connected by the logical gates. The FT shown in Figure 2 has six 'OR' gates and three 'AND' gates. A qualitative analysis can be done to the FT because the main components and their relationships are represented.

Table 1. Main faults in the converter, electrical and electronic components and generator, based on [37]. $\mathrm{c} 1-\mathrm{c} 2$ and g1-g10 are the nodes of the fault tree (FT) in Figure 2.

\begin{tabular}{|c|c|c|c|}
\hline Critical Generator Failure & g1 & Abnormal Vibration $\mathrm{G}$ & $\mathrm{c} 1$ \\
\hline Power electronics (PE) and electric controls failure & g2 & Cracks & c2 \\
\hline Mechanical failure (generator) & g3 & Imbalance & c3 \\
\hline Electrical failure (generator) & g4 & Asymmetry & c4 \\
\hline Electrical fault (PE) & g5 & Short circuit (generator) & c5 \\
\hline Mechanical fault (PE) & g6 & Open circuit (generator) & c6 \\
\hline Bearing generator fault & g7 & Gate drive circuit & c7 \\
\hline Electrical failure & g8 & Short circuit (electronics) & $\mathrm{c} 8$ \\
\hline Abnormal signals A & g9 & Open circuit (electronics) & c9 \\
\hline \multirow[t]{3}{*}{ Power electronic } & g10 & Broken bars & c10 \\
\hline & & Corrosion & $\mathrm{c} 11$ \\
\hline & & Terminals damage & c12 \\
\hline
\end{tabular}

The quantitative analysis in this study is done by the Boolean expression given by the FT-that is obtained by the BDDs. Lee [61] introduced the BDD; it was popularized by Moret [62], Akers [63] and Bryant [64]. BDDs are used to obtain the Boolean functions, leading to obtain the mathematical expression to the problem by employing, for example, the Karnaugh maps or truth tables [65]. BDD provides the cut-sets (CS), paths of the BDD "from the top to the one" where the unreliability of the system could be achieved from them. The computational cost is given by the size of the BDDs [66]. 


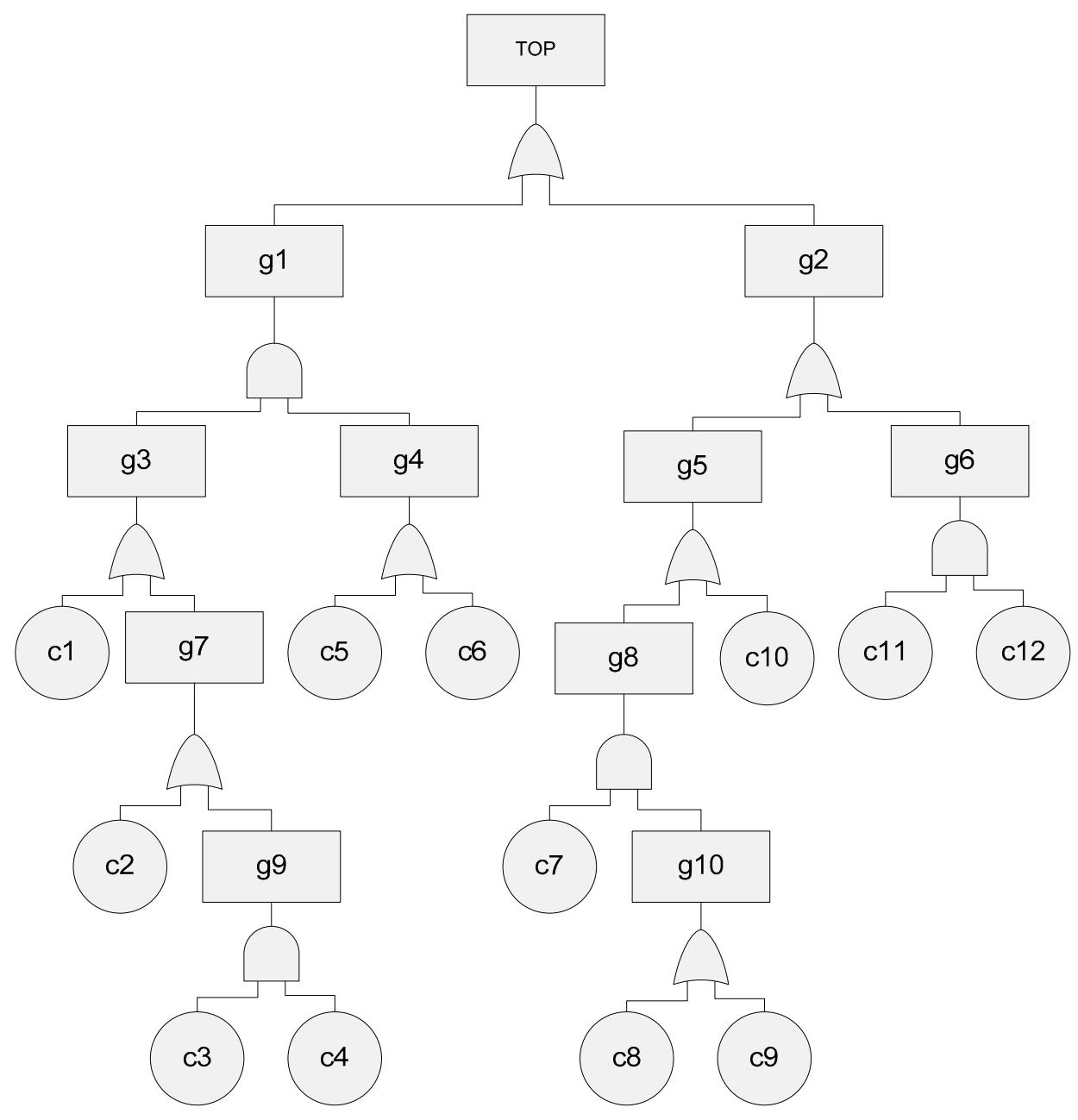

Figure 2. Fault tree example for a wind turbine (WT) (based on [37]).

It depends on the order of the events. There is not any exact method to order the events optimally. This study considers the following methods for validating the raking of the events:

- The "top-down-left-right" method (TDLR) orders the events in a top-down and then left-right way in the FT to provide a ranking of the events. At each level, the events order is initialized from left to right and the events found are set in this order [67];

- The "depth-first-search" method (DFS) orders from top to down of a root and each sub-tree works from left to right, being a non-recursive procedure where all new expanded nodes are added by last-input last-output process [68];

- The "breadth-first-search" method (BFS) orders the events by the first-input first-output (FIFO) method; A queue list, named "open", is employed to consider the events not included by the FIFO method [69];

- The "level" method orders the events regarding to the level where the events are located, being the level set by the AND gates number that there are from the event to the top event. The event that appears early in the tree will have highest priority in case that two or more events have the same level [70];

- The "AND" method assigns the order of the events according to the AND gates that the event has until the top event, because the AND gates imply redundancies in the systems. Basic events with the highest number of "and" gates will be ranked at the end. In the case of duplicated basic events, the event with less "and" gates has priority; Finally, basic events with the same number of "and" gates can be ranked as the TDLR method approach [71]; 
The above ranking methods were applied to the FT shown in Figure 2. The CSs obtained are presented in Table 2.

Table 2. Number of cut-set about the FT from Figure 2.

\begin{tabular}{cccccc}
\hline Ranking Method & TLDR & DFS & BFS & Level & AND \\
\hline Number of CSs & 38 & 22 & 23 & 26 & 23 \\
\hline
\end{tabular}

The probability of a system is given by the sum of each analytic expression of the CSs due that the CSs are mutually exclusive, i.e., the unreliability of the system is the sum of probabilities of all the BDD paths [61-63]. It can be also computed in the BDD [53]. The main advantage of a quantitative analysis using BDDs is the implicit formulation. Coudert (1994) proposed the use of the term "metaproducts" to develop implicit calculations of the BDDs [72]. Each cut set is a path from a terminal node with value 1 until the top node. The CS are mutually exclusive paths. It is necessary to consider the occurrence of some events and the non-occurrence of others to evaluate the probability of each CS. The CSs are obtained from the BDD graph, which is constructed via Shannon decomposition, where each non-terminal node has an occurrence branch (left branch) and a non-occurrence branch (right branch). These negated variables appear in those paths that go through any "non-occurrence branch" $[73,74]$. BDD has the following probabilities of each 22 cut-sets obtained by applying the DFS method (see Table 2), where $q i$ is the probability of failure of the component $i$ :

$\mathrm{CS}_{1}: \mathrm{q}_{6} \mathrm{q}_{1}$

$\mathrm{CS}_{2}: \mathrm{q}_{7}\left(1-\mathrm{q}_{6}\right) \mathrm{q}_{1}$

$\mathrm{CS}_{3}: \mathrm{q}_{10}\left(1-\mathrm{q}_{7}\right)\left(1-\mathrm{q}_{6}\right) \mathrm{q}_{1}$

$\mathrm{CS}_{4}: \mathrm{q}_{12} \mathrm{q}_{11}\left(1-\mathrm{q}_{10}\right)\left(1-\mathrm{q}_{7}\right)\left(1-\mathrm{q}_{6}\right) \mathrm{q}_{1}$

$\mathrm{CS}_{5}: \mathrm{q}_{6} \mathrm{q}_{2}\left(1-\mathrm{q}_{1}\right)$

$\mathrm{CS}_{6}: \mathrm{q}_{7}\left(1-\mathrm{q}_{6}\right) \mathrm{q}_{2}\left(1-\mathrm{q}_{1}\right)$

$\mathrm{CS}_{7}: \mathrm{q}_{10}\left(1-\mathrm{q}_{7}\right)\left(1-\mathrm{q}_{6}\right) \mathrm{q}_{2}\left(1-\mathrm{q}_{1}\right)$

$\mathrm{CS}_{8}: \mathrm{q}_{12} \mathrm{q}_{11}\left(1-\mathrm{q}_{10}\right)\left(1-\mathrm{q}_{7}\right)\left(1-\mathrm{q}_{6}\right) \mathrm{q}_{2}\left(1-\mathrm{q}_{1}\right)$

$\mathrm{CS}_{9}: \mathrm{q}_{6} \mathrm{q}_{3}\left(1-\mathrm{q}_{2}\right)\left(1-\mathrm{q}_{1}\right)$

$\mathrm{CS}_{10}: \mathrm{q}_{7}\left(1-\mathrm{q}_{6}\right) \mathrm{q}_{3}\left(1-\mathrm{q}_{2}\right)\left(1-\mathrm{q}_{1}\right)$

$\mathrm{CS}_{11}: \mathrm{q}_{10}\left(1-\mathrm{q}_{7}\right)\left(1-\mathrm{q}_{6}\right) \mathrm{q}_{3}\left(1-\mathrm{q}_{2}\right)\left(1-\mathrm{q}_{1}\right)$

$\mathrm{CS}_{12}: \mathrm{q}_{12} \mathrm{q}_{11}\left(1-\mathrm{q}_{10}\right)\left(1-\mathrm{q}_{7}\right)\left(1-\mathrm{q}_{6}\right) \mathrm{q}_{3}\left(1-\mathrm{q}_{2}\right)\left(1-\mathrm{q}_{1}\right)$

$\mathrm{CS}_{13}: \mathrm{q}_{6} \mathrm{q}_{4}\left(1-\mathrm{q}_{3}\right)\left(1-\mathrm{q}_{2}\right)\left(1-\mathrm{q}_{1}\right)$

$\mathrm{CS}_{14}: \mathrm{q}_{7}\left(1-\mathrm{q}_{6}\right) \mathrm{q}_{4}\left(1-\mathrm{q}_{3}\right)\left(1-\mathrm{q}_{2}\right)\left(1-\mathrm{q}_{1}\right)$

$\mathrm{CS}_{15}: \mathrm{q}_{10}\left(1-\mathrm{q}_{7}\right)\left(1-\mathrm{q}_{6}\right) \mathrm{q}_{4}\left(1-\mathrm{q}_{3}\right)\left(1-\mathrm{q}_{2}\right)\left(1-\mathrm{q}_{1}\right)$

$\mathrm{CS}_{16}: \mathrm{q}_{12} \mathrm{q}_{11}\left(1-\mathrm{q}_{10}\right)\left(1-\mathrm{q}_{7}\right)\left(1-\mathrm{q}_{6}\right) \mathrm{q}_{4}\left(1-\mathrm{q}_{3}\right)\left(1-\mathrm{q}_{2}\right)\left(1-\mathrm{q}_{1}\right)$

$\mathrm{CS}_{17}: \mathrm{q}_{10} \mathrm{q}_{7}\left(1-\mathrm{q}_{4}\right)\left(1-\mathrm{q}_{3}\right)\left(1-\mathrm{q}_{2}\right)\left(1-\mathrm{q}_{1}\right)$

$\mathrm{CS}_{18}: \mathrm{q}_{8}\left(1-\mathrm{q}_{10}\right) \mathrm{q}_{7}\left(1-\mathrm{q}_{4}\right)\left(1-\mathrm{q}_{3}\right)\left(1-\mathrm{q}_{2}\right)\left(1-\mathrm{q}_{1}\right)$

$\mathrm{CS}_{19}: \mathrm{q}_{9}\left(1-\mathrm{q}_{8}\right)\left(1-\mathrm{q}_{10}\right) \mathrm{q}_{7}\left(1-\mathrm{q}_{4}\right)\left(1-\mathrm{q}_{3}\right)\left(1-\mathrm{q}_{2}\right)\left(1-\mathrm{q}_{1}\right)$

$\mathrm{CS}_{20}: \mathrm{q}_{12} \mathrm{q}_{11}\left(1-\mathrm{q}_{9}\right)\left(1-\mathrm{q}_{8}\right)\left(1-\mathrm{q}_{10}\right) \mathrm{q}_{7}\left(1-\mathrm{q}_{4}\right)\left(1-\mathrm{q}_{3}\right)\left(1-\mathrm{q}_{2}\right)\left(1-\mathrm{q}_{1}\right)$

$\mathrm{CS}_{21}: \mathrm{q}_{10}\left(1-\mathrm{q}_{7}\right)\left(1-\mathrm{q}_{4}\right)\left(1-\mathrm{q}_{3}\right)\left(1-\mathrm{q}_{2}\right)\left(1-\mathrm{q}_{1}\right)$

$\mathrm{CS}_{22}: \mathrm{q}_{12} \mathrm{q}_{11}\left(1-\mathrm{q}_{10}\right)\left(1-\mathrm{q}_{7}\right)\left(1-\mathrm{q}_{4}\right)\left(1-\mathrm{q}_{3}\right)\left(1-\mathrm{q}_{2}\right)\left(1-\mathrm{q}_{1}\right)$

BDD associated with the FT from Figure 2 is shown in Figure 3. 


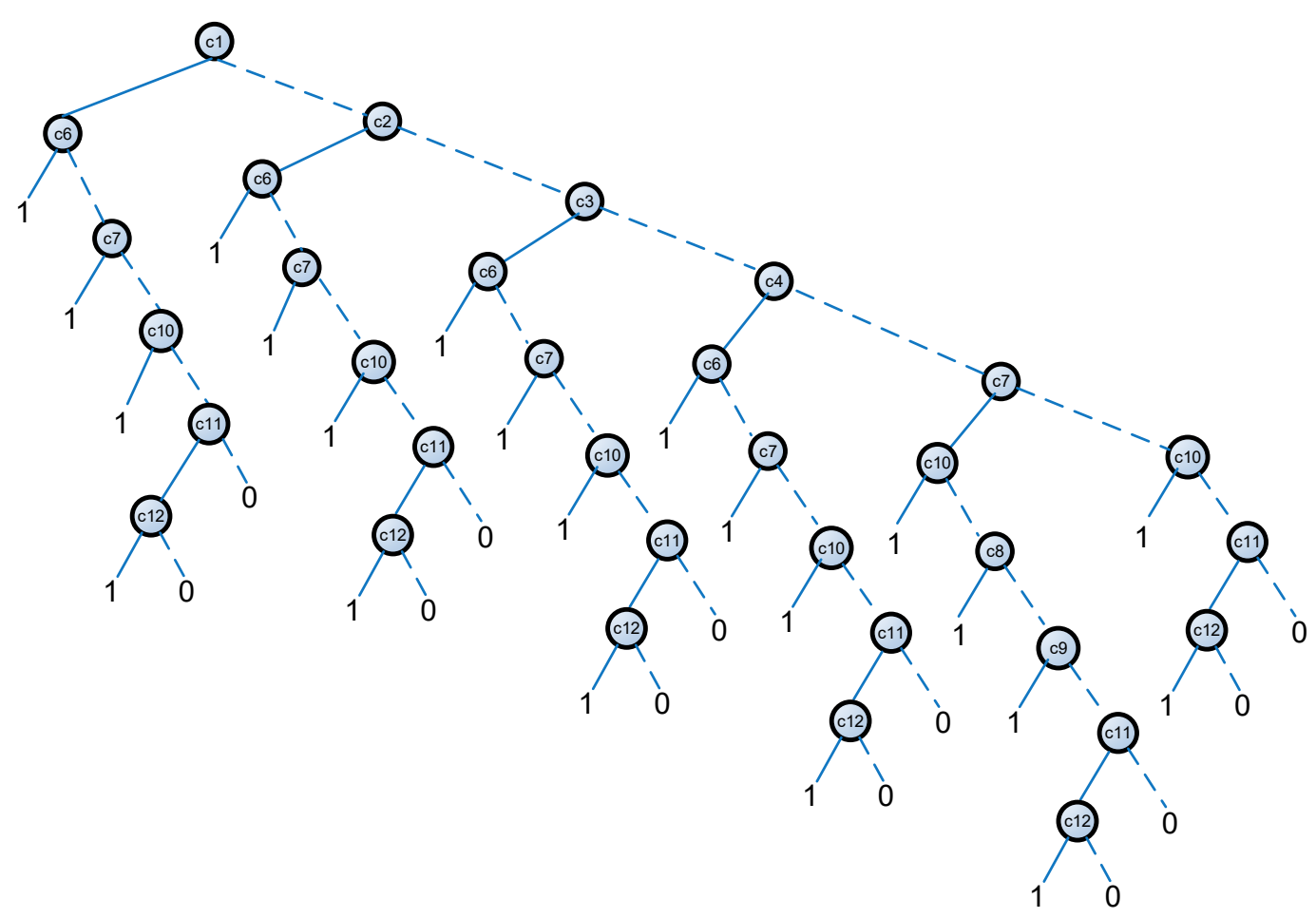

Figure 3. BDD of the FT from Figure 2, obtained by the depth-first-search (DFS) method (see Table 2).

\section{Dynamic Analysis}

Time-dependent unreliability functions are considered in this study to describe the behavior of the main components over the time. The aim of these models is to bring probability function of unreliability as close as possible to a real case study. The functions considered are:

a. Constant unreliability The probability of the events or components is constant over the time. $Q(t)=\mathrm{K}$, where $\mathrm{K}$ is a constant valued between 0 and 1 .

b. Exponential increasing unreliability The probability function assigned is defined in Equation (1):

$$
Q(t)=1-e^{-\lambda t}
$$

where $\lambda$ is a parameter that takes only positive values and determines how quickly the unreliability increases.

c. Linear decreasing reliability The probability function is defined in Equation (2):

$$
Q(t)=1-m t,
$$

where $m$ determines how quickly the unreliability decreases. This model could be acceptable for infant failures of those components that are in the decreasing failure rate of their lifecycle.

d. Periodic unreliability The unreliability of the components has a periodic behavior. The expression used for this assignment is given by Equation (3):

$$
Q(t)=1-e^{-\lambda(t-n \alpha)}
$$

with $n=1,2,3 \ldots$, where:

- $\lambda$ is a parameter that takes only positive values and determines the velocity of the unreliability rising.

- $\quad \alpha$ is a parameter that determines the size of the period 
Several unreliability models were considered for each component to analyze the FT in Figure 2. The most important parameters are shown in Table 3.

Table 3. Unreliability models.

\begin{tabular}{lcc}
\hline Components & Probability Model & Parameters \\
\hline Component 1 & Constant & $\mathrm{K}=0.5$ \\
Component 2 & Exponential increasing & $\lambda=0.2$ \\
Component 3 & Constant & $\mathrm{K}=0.025$ \\
Component 4 & Periodic & $\lambda=0.51, \alpha=2$ \\
Component 5 & Exponential increasing & $\lambda=0.4$ \\
Component 6 & Constant & $\mathrm{K}=0.01$ \\
Component 7 & Exponential increasing & $\lambda=0.25$ \\
Component 8 & Linear decreasing & $m=0.16$ \\
Component 9 & Constant & $\mathrm{K}=0.09$ \\
Component 10 & Periodic & $\lambda=0.46, \alpha=1.5$ \\
Component 11 & Linear decreasing & $m=0.16$ \\
Component 12 & Periodic & $\lambda=0.7, \alpha=0.8$ \\
\hline
\end{tabular}

Figure 4 shows the unreliability of each component obtained in 50 samples (units of time). Ten samples were considered for each unit of time. The methods used to perform the qualitative and quantitative analysis on the BDD are shown in reference [56]. The dash lines represent the unreliability of the basic components. The solid black line shows the unreliability of the global system obtained by the BDD.

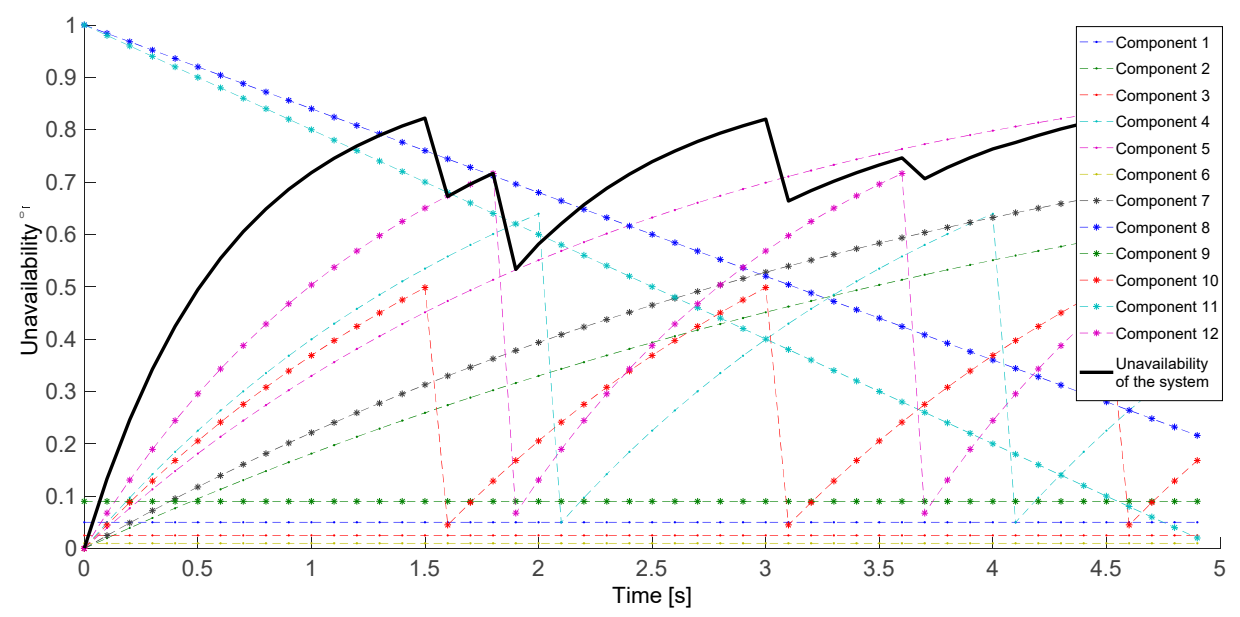

Figure 4. Unreliability of a system.

Figure 4 also allows to obtain a first approach to the importance of components within the global system. It can be seen that components 12 and 10 have an important influence into the system, where a direct relation between the own unreliability of these components and the unreliability of the global system can be observed. A sudden change in the unreliability of the components causes the unreliability of the system to change abruptly. Oppositely, it can be observed that the components whose unreliability is linear decreasing (Components 8 and 11), do not have a relevant importance within the global system.

A reliable measure of the importance of each component is required to determine it quantitatively.

\section{Importance Measurement}

IMs are employed to set the influence of each component over the FT. There are several methods for measuring the importance of components. This study will consider the most common: Birnbaum and criticality. Further information about these and more IMs is possible to be found in reference [7]. 
Birnbaum IM [75] gives the value associated with the direct relation between the unreliability of the system and the corresponding component. It is defined in Equation (4) as follows:

$$
I_{k}^{\text {Birn }}=\frac{\partial Q_{\text {system }}}{\partial Q_{k}}
$$

where:

- $\quad I_{k}^{\text {Birn }}$ is the Birnbaum IM value of the $k$ th component;

- $Q_{\text {system, }}$ is the unreliability of the system;

- $Q_{k}$, is the probability assigned to the $k$ th component.

Figure 5 shows a time-dependent Birnbaum IM for each component (event). This graph can be useful in order to determine the most relevant component at any time. If repairs were necessary at a certain moment, this solution set offers a ranking for the components that should be repaired or replaced in first place. For instance, if the unreliability of the system exceeds the established limit at sample 2, it can be observed easily that component 7 should be repaired or replaced in first place.

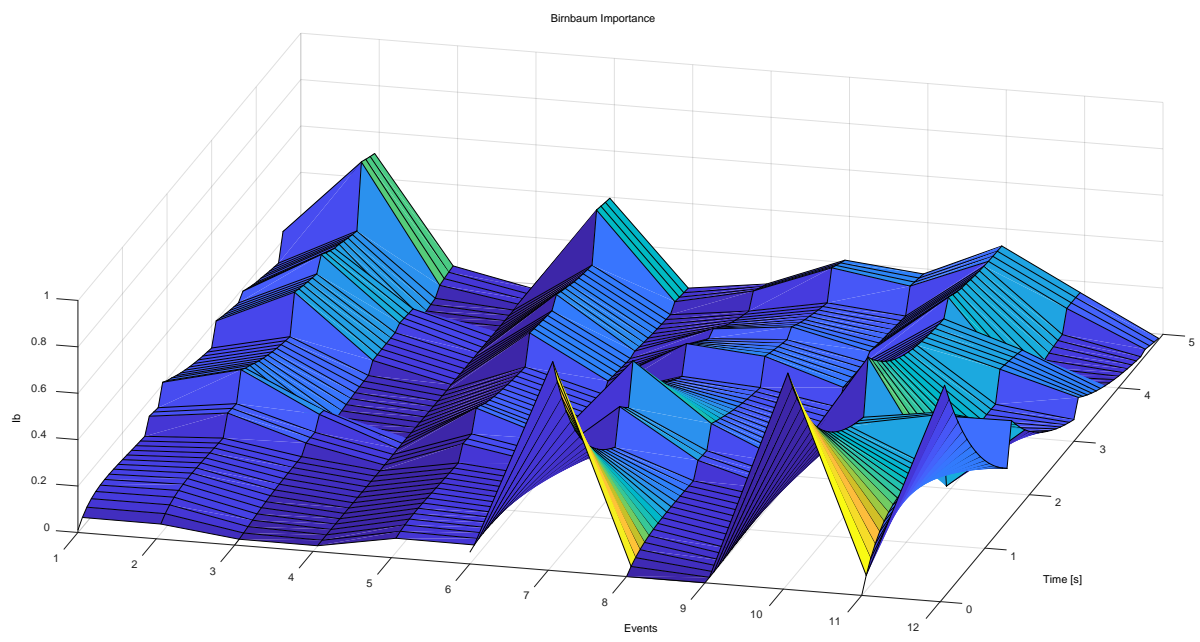

Figure 5. Time-dependent Birnbaum: time in seconds.

A disadvantage of Birnbaum IM is that it does not consider the unreliability of the component itself. This can lead to consider a major importance than it should be for components with a low probability of occurrence. criticality IM [76], unlike Birnbaum, has into account the probability of occurrence of the event itself. It rectifies the drawbacks presented in Birnbaum IM, balancing the values obtained.

It is characterized in Equation (5):

$$
\mathrm{I}_{\mathrm{k}}^{\text {Crit }}=\frac{\mathrm{Q}_{\mathrm{k}}}{\mathrm{Q}_{\text {system }}} \cdot \frac{\partial \mathrm{Q}_{\text {system }}}{\partial \mathrm{Q}_{\mathrm{k}}}=\frac{\mathrm{Q}_{\mathrm{k}}}{\mathrm{Q}_{\mathrm{system}}} \cdot \mathrm{I}_{\mathrm{k}}^{\text {Birn }}
$$

where:

- $\quad \mathrm{I}_{\mathrm{k}}^{\text {Crit }}$ is the Birnbaum IM of the $k$ th component;

- $\mathrm{Q}_{\mathrm{k}}$ is the probability assigned to the $k$ th component;

- $\mathrm{Q}_{\text {system }}$ is the unreliability of the system.

Figure 6 shows how criticality provides a different perspective than the one showed by Birnbaum IM, even though both are connected. It is important to note that there are components that had great Birnbaum Importance and Low criticality Importance. This means that mentioned components are 
essential for the system to work, but their unreliability values are so insignificant that no repairs are recommended upon them.

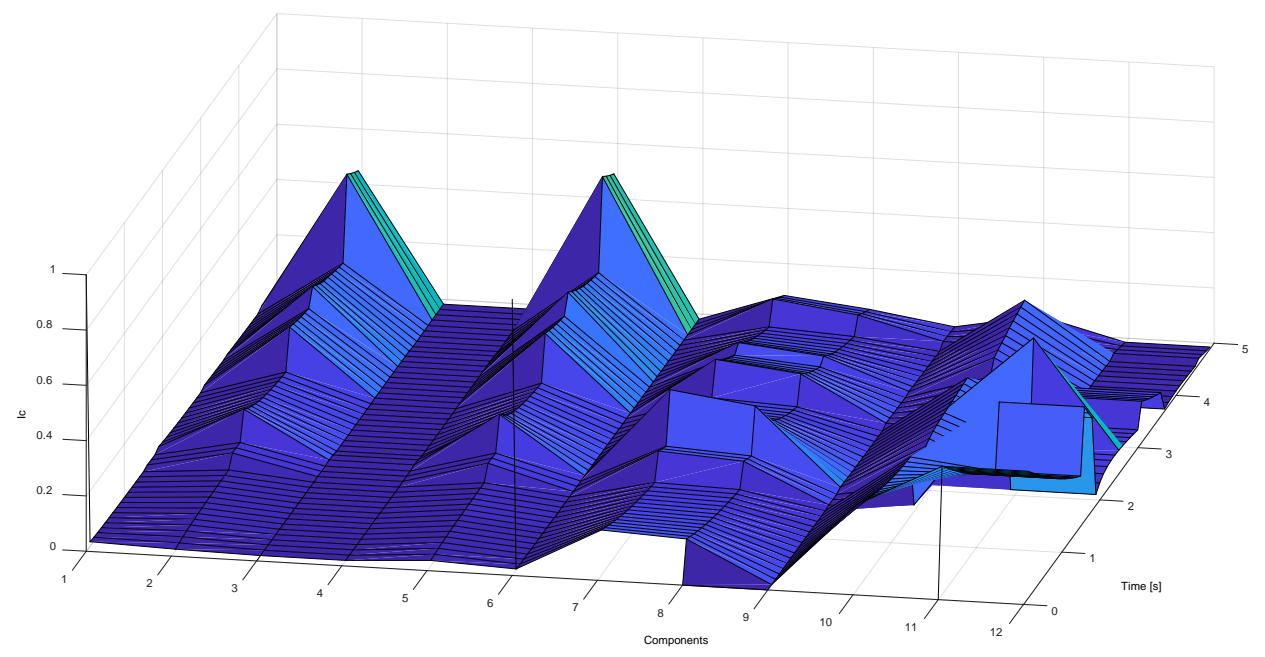

Figure 6. Time-dependent ccriticality: time in seconds.

\section{Procedure for Maintenance}

Applying temporary variables allows determining operational strategies that will raise the reliability of the system. It will also lead to the following issues:

- To determine the reliability of the system and its components at a certain moment;

- To identify critical operating states of the system and its components;

- To determine the optimal time to carry out a preventive task and to choose the components to be repaired or replaced;

- To determine the repairs or replacements necessary to ensure a certain reliability of the system for a period of time.

Firms frequently need to guarantee certain reliability for their systems or products because a low reliability can lead to unprofitable situations. For instance, the image of a firm could be seriously affected by unreliable products. For this reason, firms usually establish a degree of reliability for their systems or products. Figure 7 shows a simple threshold (dash line) for unreliability of the WT depicted in Figure 2. The first intersection between the two lines provides the limit that the system has an acceptable unreliability rate. This point also fixes the moment in which certain repairs should be done to maintain an acceptable unreliability. Once this point was localized (time $=0.7$ in Figure 7 ), then next step is to select the components to repair from the IMs obtained previously. Once components were repaired or replaced, the unreliability will be acceptable again. This iterative process constitutes a good strategy for ensure a certain reliability of the system for a certain period of time.

Moreover, the identification of maximum unreliability points allows determining the degree of criticality by evaluating the distance between these points and the corresponding threshold. 


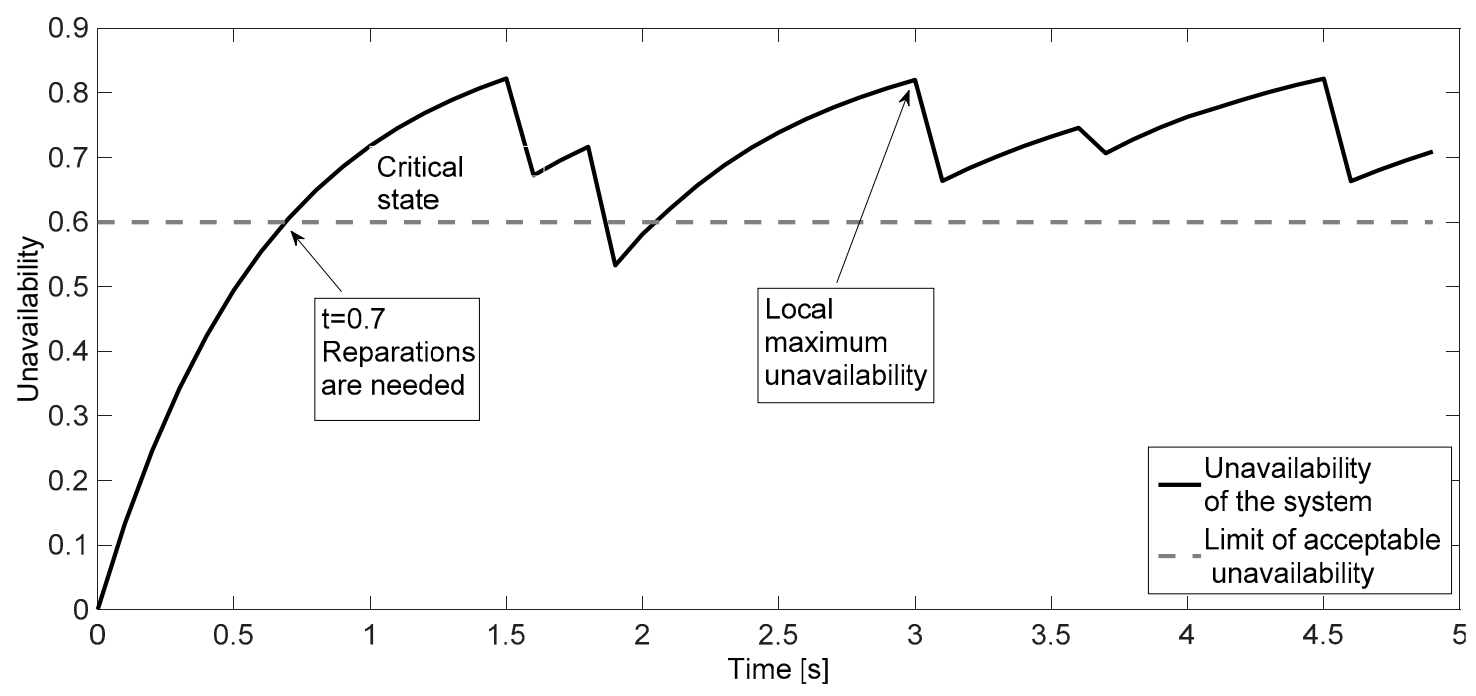

Figure 7. Unreliability threshold for a WT.

\section{Conclusions}

This study presents a novel approach to facilitate quantitative reliability analysis of complex systems based on the qualitatively analysis. For this purpose, FTs and BDDs are presented as the method and applied to a case study in WT. FTs are used to depict the operation of a system and the logical interrelations between its components. Building a FT requires a profound knowledge of the system, but it is a useful tool to make a previous qualitative analysis. BDDs are used for carrying out quantitative analysis, where they provide a function of the unreliability of the global system. This function depends on the unreliability of the components that compose the system. Different failure probability distributions (Section 3) are used in this study to model the behavior of these components. The reliability analysis aims to achieve an efficient maintenance strategy to keep the unreliability of the system below a desired threshold. It is necessary to define two factors to achieve this: when repairs should be made, and which components that should be repaired. The first is determined by the intersection of the unreliability of the system and the threshold. The second is obtained from IMs: Birnbaum or criticality. An iterative process is suggested to define a strategy able to ensure a correct reliability for a certain period of time.

For future works, we propose considering and analyzing larger and more complex FT in WT and other systems and to study the efficiency of ranking methods employed in this study. New IM methods should be also considered. Therefore, this could improve the WT reliability assessment based on the FTA.

Author Contributions: Funding acquisition, Project administration and Supervision, F.P.G.M.; Data curation, I.S.R. and A.P.M.; Visualization, F.P.G.M., I.S.R. and A.P.M.; Formal Analysis, Resources, F.P.G.M. and A.P.M.; Investigation, F.P.G.M., I.S.R., A.P.M and B.M.-I.; Methodology, F.P.G.M., B.M.-I. and A.P.M.; Software and Validation, A.P.M. and B.M.-I.; Writing-original draft, I.S.R., A.P.M. and B.M.-I.; Writing-review and editing, F.P.G.M. and B.M.-I. All authors have read and agreed to the published version of the manuscript.

Funding: The work reported herewith was financially by the Dirección General de Universidades, Investigación e Innovación of Castilla-La Mancha, under Research Grant ProSeaWind project (Ref.: SBPLY/19/180501/000102) and the Spanish Ministerio de Economía y Competitividad, under Re-search Grants DPI2015-67264-P.

Conflicts of Interest: The authors declare no conflict of interest.

\section{References}

1. Muñoz, C.Q.G.; Márquez, F.P.G. Future maintenance management in renewable energies. In Renewable Energies; Springer: Berlin/Heidelberg, Germany, 2018; pp. 149-159.

2. Council, G.W.E. Global Wind Report; GWEC: Brussels, Belgium, 2019. 
3. Qiao, W.; Lu, D. A survey on wind turbine condition monitoring and fault diagnosis—part i: Components and subsystems. IEEE Trans. Ind. Electron. 2015, 62, 6536-6545. [CrossRef]

4. Marquez, F.G. An approach to remote condition monitoring systems management. In Proceedings of the 2006 IET International Conference On Railway Condition Monitoring, Birmingham, UK, 29-30 November 2006.

5. Márquez, F.P.G.; Pedregal, D.J. Applied RCM2 algorithms based on statistical methods. Int. J. Autom. Comput. 2007, 4, 109-116. [CrossRef]

6. Njiri, J.G.; Soeffker, D. State-of-the-art in wind turbine control: Trends and challenges. Renew. Sustain. Energy Rev. 2016, 60, 377-393. [CrossRef]

7. Spiess, H.; Lobsiger-Kägi, E.; Carabias-Hütter, V.; Marcolla, A. Future acceptance of wind energy production: Exploring future local acceptance of wind energy production in a swiss alpine region. Technol. Forecast. Soc. Chang. 2015, 101, 263-274. [CrossRef]

8. Petković, D.; Pavlović, N.T.; Ćojbašić, Ž. Wind farm efficiency by adaptive neuro-fuzzy strategy. Int. J. Electr. Power Energy Syst. 2016, 81, 215-221. [CrossRef]

9. Márquez, F.P.G.; Lev, B. Advanced Business Analytics; Springer: Berlin/Heidelberg, Germany, 2015.

10. Sarker, B.R.; Faiz, T.I. Minimizing maintenance cost for offshore wind turbines following multi-level opportunistic preventive strategy. Renew. Energy 2016, 85, 104-113. [CrossRef]

11. Pliego Marugán, A.; García Márquez, F.P. Advanced analytics for detection and diagnosis of false alarms and faults: A real case study. Wind Energy 2019, 22, 1622-1635. [CrossRef]

12. Márquez, F.P.G.; Pardo, I.P.G.; Nieto, M.R.M. Competitiveness based on logistic management: A real case study. Ann. Oper. Res. 2015, 233, 157-169.

13. Shafiee, M.; Sørensen, J.D. Maintenance optimization and inspection planning of wind energy assets: Models, methods and strategies. Reliab. Eng. Syst. Saf. 2019, 192, 105993. [CrossRef]

14. Tavner, P.; Gindele, R.; Faulstich, S.; Hahn, B.; Whittle, M.; Greenwood, D. Study of Effects of Weather \& Location on Wind Turbine Failure Rates. In Proceedings of the European Wind Energy Conference EWEC, Warsaw, Poland, 15 March 2010.

15. Marquez, F.G.; Singh, V.; Papaelias, M. A Review of Wind Turbine Maintenance Management Procedures. In Proceedings of the Eighth International Conference on Condition Monitoring and Machinery Failure Prevention Technologies, Cardiff, UK, 20-22 June 2011; pp. 1-14.

16. Márquez, F.P.G.; Karyotakis, A.; Papaelias, M. Renewable Energies: Business Outlook 2050; Springer: Berlin/Heidelberg, Germany, 2018.

17. Pérez, J.M.P.; Márquez, F.P.G.; Hernández, D.R. Economic viability analysis for icing blades detection in wind turbines. J. Clean. Prod. 2016, 135, 1150-1160. [CrossRef]

18. Bangalore, P.; Patriksson, M. Analysis of scada data for early fault detection, with application to the maintenance management of wind turbines. Renew. Energy 2018, 115, 521-532. [CrossRef]

19. Marugán, A.P.; Márquez, F.P.G.; Papaelias, M. Multivariable Analysis for Advanced Analytics of Wind Turbine Management. In Proceedings of the Tenth International Conference on Management Science and Engineering Management, Baku, Azerbaijan, 30 August-2 September 2016; pp. 319-328.

20. Márquez, F.P.G. A new method for maintenance management employing principal component analysis. Struct. Durab. Health Monit. 2010, 6, 89-99.

21. Pedregal, D.J.; García, F.P.; Roberts, C. An algorithmic approach for maintenance management based on advanced state space systems and harmonic regressions. Ann. Oper. Res. 2009, 166, 109-124. [CrossRef]

22. Marugán, A.P.; Chacón, A.M.P.; Márquez, F.P.G. Reliability analysis of detecting false alarms that employ neural networks: A real case study on wind turbines. Reliab. Eng. Syst. Saf. 2019, 191, 106574. [CrossRef]

23. Schlechtingen, M.; Santos, I.F. Comparative analysis of neural network and regression based condition monitoring approaches for wind turbine fault detection. Mech. Syst. Signal Process. 2011, 25, 1849-1875. [CrossRef]

24. Gómez Muñoz, C.Q.; García Marquez, F.P.; Hernandez Crespo, B.; Makaya, K. Structural health monitoring for delamination detection and location in wind turbine blades employing guided waves. Wind Energy 2019, 22, 698-711. [CrossRef]

25. Arcos Jiménez, A.; Gómez Muñoz, C.Q.; García Márquez, F.P. Machine learning for wind turbine blades maintenance management. Energies 2018, 11, 13. [CrossRef] 
26. Gómez, C.; García, F.; Arcos, A.; Cheng, L.; Kogia, M.; Mohimi, A.; Papaelias, M. A heuristic method for detecting and locating faults employing electromagnetic acoustic transducers. Eksploat. Niezawodn. 2017, 19. [CrossRef]

27. Gómez, C.Q.; Villegas, M.A.; García, F.P.; Pedregal, D.J. Big data and web intelligence for condition monitoring: A case study on wind turbines. In Big Data: Concepts, Methodologies, Tools, and Applications; IGI Global: Hershey, PA, USA, 2016; pp. 1295-1308.

28. Ramirez, I.S.; Muñoz, C.Q.G.; Marquez, F.P.G. A condition monitoring system for blades of wind turbine maintenance management. In Proceedings of the Tenth International Conference on Management Science and Engineering Management, Baku, Azerbaijan, 30 August-2 September 2016; pp. 3-11.

29. Roshanmanesh, S.; Hayati, F.; Kappatos, V.; Marquez, F.P.G.; Marugán, A.P.; Muñoz, C.Q.G.; Selcuk, C.; Gan, T.-H.; Papaelias, M. Drive-Train Condition Monitoring for Offshore Wind and Tidal Turbines, 2nd ed. In Proceedings of the International Conference on Renewable Energies Offshore (Renew 2016), Lisbon, Portugal, 24-26 October 2016.

30. Jiménez, A.A.; Márquez, F.P.G.; Moraleda, V.B.; Muñoz, C.Q.G. Linear and nonlinear features and machine learning for wind turbine blade ice detection and diagnosis. Renew. Energy 2019, 132, 1034-1048. [CrossRef]

31. García Márquez, F.P.; Segovia Ramírez, I.; Pliego Marugán, A. Decision making using logical decision tree and binary decision diagrams: A real case study of wind turbine manufacturing. Energies 2019, 12, 1753. [CrossRef]

32. Pliego Marugán, A.; García Márquez, F.P.; Lev, B. Optimal decision-making via binary decision diagrams for investments under a risky environment. Int. J. Prod. Res. 2017, 55, 5271-5286. [CrossRef]

33. Kempener, R.; Assoumou, E.; Chiodi, A.; Ciorba, U.; Gaeta, M.; Gielen, D.; Hamasaki, H.; Kanudia, A.; Kober, T.; Labriet, M. A global renewable energy roadmap: Comparing energy systems models with irena's remap 2030 project. In Informing Energy and Climate Policies Using Energy Systems Models; Springer: Berlin/Heidelberg, Germany, 2015; pp. 43-67.

34. Muñoz, C.Q.G.; Márquez, F.P.G.; Tomás, J.M.S. Ice detection using thermal infrared radiometry on wind turbine blades. Measurement 2016, 93, 157-163. [CrossRef]

35. Jiménez, A.A.; Zhang, L.; Muñoz, C.Q.G.; Márquez, F.P.G. Maintenance management based on machine learning and nonlinear features in wind turbines. Renew. Energy 2020, 146, 316-328. [CrossRef]

36. García Márquez, F.P.; García-Pardo, I.P. Principal component analysis applied to filtered signals for maintenance management. Qual. Reliab. Eng. Int. 2010, 26, 523-527. [CrossRef]

37. Garcia Marquez, F.P.; Pliego Marugan, A.; Pérez, P.; María, J.; Hillmansen, S.; Papaelias, M. Optimal dynamic analysis of electrical/electronic components in wind turbines. Energies 2017, 10, 1111. [CrossRef]

38. Pliego Marugán, A.; Garcia Márquez, F.P. Fault-tree dynamic analysis. In Proceedings of the Eleventh International Conference on Condition Monitoring and Machinery Failure Prevention Technologies CM, Manchester, UK, 10-12 June 2014; pp. 10-12.

39. Márquez, F.P.G.; Pérez, J.M.P.; Marugán, A.P.; Papaelias, M. Identification of critical components of wind turbines using fta over the time. Renew. Energy 2016, 87, 869-883. [CrossRef]

40. Márquez, F.G.; Papaelias, J.; Hermosa, R.R. Wind turbines maintenance management based on fta and bdd. In Proceedings of the International Conference on Renewable Energies and Power Quality (ICREPQ'12), Santiago de Compostela, Spain, 28-30 March 2012; pp. 4-6.

41. Lee, J.; Ye, Y.-H.; Huang, X.; Yang, R.-L. Binary-decision-diagram-based decomposition of boolean functions into reversible logic elements. Theor. Comput. Sci. 2020, 814, 120-134. [CrossRef]

42. Jiménez, A.A.; Muñoz, C.Q.G.; Márquez, F.P.G. Dirt and mud detection and diagnosis on a wind turbine blade employing guided waves and supervised learning classifiers. Reliab. Eng. Syst. Saf. 2019, 184, 2-12. [CrossRef]

43. Muñoz, C.Q.G.; Marquez, F.P.G.; Lev, B.; Arcos, A. New pipe notch detection and location method for short distances employing ultrasonic guided waves. Acta Acust. United Acust. 2017, 103, 772-781. [CrossRef]

44. Pedro, F.; Marquez, G. Binary decision diagrams applied to fault tree analysis. In Proceedings of the 4th IET International Conference on Railway Condition Monitoring (RCM 2008), Birmingham, UK, 18-20 June 2008.

45. Li, Z.; Wang, Z.; Ren, Y.; Yang, D.; Lv, X. A novel reliability estimation method of multi-state system based on structure learning algorithm nowatorska metoda oceny niezawodności systemów wielostanowych $\mathrm{w}$ oparciu o algorytm uczenia struktury. Eksploatacja I Niezawodnosc 2020, 22, 170. [CrossRef] 
46. Wang, H.; Duan, F.; Ma, J. Reliability analysis of complex uncertainty multi-state system based on bayesian network zastosowanie sieci bayesowskiej do analizy niezawodności złożonych systemów wielostanowych w warunkach niepewności. Eksploatacja I Niezawodnosc 2019, 21, 419. [CrossRef]

47. Bucci, P.; Kirschenbaum, J.; Mangan, L.A.; Aldemir, T.; Smith, C.; Wood, T. Construction of event-tree/fault-tree models from a markov approach to dynamic system reliability. Reliab. Eng. Syst. Saf. 2008, 93, 1616-1627. [CrossRef]

48. Bhagavatula, A.; Tao, J.; Dunnett, S.; Bell, P. A New Methodology for Automatic Fault Tree Construction Based on Component and Mark Libraries; Safety and Reliability; Taylor \& Francis: Abingdon, UK, 2016; pp. 62-76.

49. Majdara, A.; Wakabayashi, T. Component-based modeling of systems for automated fault tree generation. Reliab. Eng. Syst. Saf. 2009, 94, 1076-1086. [CrossRef]

50. Liu, X.; Wang, Z.; Ren, Y.; Liu, L. Modeling method of sysml-based reliability block diagram. In Proceedings of the 2013 International Conference on Mechatronic Sciences, Electric Engineering and Computer (MEC), Shenyang, China, 20-22 December 2013; pp. 206-209.

51. Li, K.; Yi, R.; Ma, Z. Reliability analysis of dynamic reliability blocks through conversion into dynamic bayesian networks. In Proceedings of the 2016 IEEE International Conference on Industrial Engineering and Engineering Management (IEEM), Bali, Indonesia, 5-7 December 2016; pp. 1330-1334.

52. Mi, J.; Li, Y.; Huang, H.-Z.; Liu, Y.; Zhang, X. Reliability analysis of multi-state systems with common cause failure based on bayesian networks. In Proceedings of the 2012 International Conference on Quality, Reliability, Risk, Maintenance, and Safety Engineering, Chengdu, China, 15-18 June 2012; pp. 1117-1121.

53. Montani, S.; Portinale, L.; Bobbio, A.; Codetta-Raiteri, D. Radyban: A tool for reliability analysis of dynamic fault trees through conversion into dynamic bayesian networks. Reliab. Eng. Syst. Saf. 2008, 93, 922-932. [CrossRef]

54. Rauzy, A. Mathematical foundations of minimal cutsets. IEEE Trans. Reliab. 2001, 50, 389-396. [CrossRef]

55. Dutuit, Y.; Rauzy, A. Efficient algorithms to assess component and gate importance in fault tree analysis. Reliab. Eng. Syst. Saf. 2001, 72, 213-222. [CrossRef]

56. Marugan, A.P.; Márquez, F.P.G. Decision-Making Management: A Tutorial and Applications; Academic Press: Cambridge, MA, USA, 2017.

57. Hansen, A.D.; Michalke, G. Fault ride-through capability of dfig wind turbines. Renew. Energy 2007, 32, 1594-1610. [CrossRef]

58. Lu, B.; Li, Y.; Wu, X.; Yang, Z. A review of recent advances in wt condition monitoring and fault diagnosis. In Proceedings of the Power Electronics and Machines in Wind Applications, Lincoln, NE, USA, 24-26 June 2009; pp. 24-26.

59. Popa, L.M.; Jensen, B.-B.; Ritchie, E.; Boldea, I. Condition monitoring of wind generators. In Proceedings of the 38th IAS Annual Meeting on Conference Record of the Industry Applications Conference, Salt Lake City, UT, USA, 12-16 October 2003; pp. 1839-1846.

60. Wu, A.P.; Chapman, P.L. Simple expressions for optimal current waveforms for permanent-magnet synchronous machine drives. IEEE Trans. Energy Convers. 2005, 20, 151-157. [CrossRef]

61. Lee, C.-Y. Representation of switching circuits by binary-decision programs. Bell Syst. Tech. J. 1959, 38, 985-999. [CrossRef]

62. Moret, B.M. Decision trees and diagrams. ACM Comput. Surv. (CSUR) 1982, 14, 593-623. [CrossRef]

63. Akers, S.B. Binary decision diagrams. IEEE Trans. Comput. 1978, C-27, 509-516. [CrossRef]

64. Bryant, R.E. Graph-based algorithms for boolean function manipulation. Comput. IEEE Trans. 1986, 100, 677-691. [CrossRef]

65. Fujita, M.; Fujisawa, H.; Kawato, N. Evaluation and Improvement of Boolean Comparison Method Based on Binary Decision Diagrams; ICCAD, Citeseer: Santa Clara, CA, USA, 1988; pp. 2-5.

66. Pliego Marugán, A.; García Márquez, F.P.; Lorente, J. Decision making process via binary decision diagram. Int. J. Manag. Sci. Eng. Manag. 2015, 10, 3-8. [CrossRef]

67. Bartlett, L.M. Progression of the binary decision diagram conversion methods. In In Proceedings of the 21st International SystemsSafety Conference, Ottowa, ON, Canada, 2-4 August 2003.

68. Cormen, T.H.; Leiserson, C.E.; Rivest, R.L.; Stein, C. Elementary graph algorithms. Introd. Algorithms 2009, 1, 540-549.

69. Jensen, R.M.; Veloso, M.M. Obdd-based universal planning for synchronized agents in non-deterministic domains. J. Artif. Intell. Res. 2000, 13, 189-226. [CrossRef] 
70. Malik, S.; Wang, A.R.; Brayton, R.K.; Sangiovanni-Vincentelli, A. Logic verification using binary decision diagrams in a logic synthesis environment. In Proceedings of the IEEE International Conference on Computer-Aided Design (ICCAD-89) Digest of Technical Papers, Santa Clara, CA, USA, 7-10 November 1988; pp. 6-9.

71. Xie, M.; Tan, K.; Goh, K.; Huang, X. Optimum prioritisation and resource allocation based on fault tree analysis. Int. J. Qual. Reliab. Manag. 2000, 17, 189-199. [CrossRef]

72. Coudert, O.; Madre, J.C. Metaprime: An interactive fault-tree analyzer. IEEE Trans. Reliab. 1994, 43, $121-127$. [CrossRef]

73. Reay, K.A.; Andrews, J.D. A fault tree analysis strategy using binary decision diagrams. Reliab. Eng. Syst. Saf. 2002, 78, 45-56. [CrossRef]

74. Jung, W.S.; Han, S.H.; Ha, J. A fast bdd algorithm for large coherent fault trees analysis. Reliab. Eng. Syst. Saf. 2004, 83, 369-374. [CrossRef]

75. Borgonovo, E. Differential, criticality and birnbaum importance measures: An application to basic event, groups and sscs in event trees and binary decision diagrams. Reliab. Eng. Syst. Saf. 2007, 92, 1458-1467. [CrossRef]

76. Cheok, M.C.; Parry, G.W.; Sherry, R.R. Use of importance measures in risk-informed regulatory applications. Reliab. Eng. Syst. Saf. 1998, 60, 213-226. [CrossRef]

(C) 2020 by the authors. Licensee MDPI, Basel, Switzerland. This article is an open access article distributed under the terms and conditions of the Creative Commons Attribution (CC BY) license (http://creativecommons.org/licenses/by/4.0/). 